\title{
An Emerging Technology: Augmented Reality to Promote Learning
}

\author{
https://doi.org/10.3991/ijet.v12.i11.7354 \\ Fezile Ozdamli( $\left.{ }^{\square}\right)$, Cigdem Hursen \\ Near East University, Nicosia, Cyprus \\ fezile.ozdamli@neu.edu.tr
}

\begin{abstract}
This study aims to determine the benefits and limitations of AR applications in computer hardware education, when used as a supplementary technology, as well as examining their impact on reflective thinking skills. The study was designed according to pre-test post-test research model with experimental and control groups. The teacher candidates studied the 3D visuals both in and out of the classroom by scanning the markers in their books. In addition, they watched educational animations and videos on required subjects. As a result, in this study where Augmented Reality applications assisted with reflective learning skills were implemented in a computer hardware course, teacher candidates generally reported positive views and suggestions regarding AR applications.
\end{abstract}

Keywords-Augmented reality, reflective learning, hardware course, teacher candidates

\section{$1 \quad$ Introduction}

Although traditional teaching methods have produced many successful outcomes, nowadays educational institutions are in search of methods which will improve students' intellectual capacities and their learning experiences [1]. Nincarean, Alia, Halim, \& Rahman [2] state that even though existing methods work, there is an increasing interest among both educators and researchers to examine more practical methods, particularly since the proliferation of technology and its integration into education gained significance. The manifestation of digital technology has resulted in an escalation in the use of e-learning in higher education. Mayer [3], a supporter of the multimedia theory, states that presenting texts together with visuals enables students to form both verbal and cognitive models and also a connection between the two. Emerging tools, social media and virtual environments are providing both students and educators with the opportunity to create new learning environments [4]. The current developments in technology have had a positive impact on the interaction of media content and the quality of learning platforms; thus, there has been an immense increase in the usage of e-learning tools. In fact, technology has become integrated into education and the results have a positive impact on the teaching-learning process [5]. Moreover, previous studies show that technology-assisted learning creates a more 
innovative teaching and learning styles [6]. The richness of the digital learning resources and communication tools in e-learning promotes reflective engagement in the learning process $[7 ; 8]$. Mobile devices, in particular, have become a part of daily lives and their applications in education have been discovered by educators and researchers. Mobile applications which can be used in education, learning management systems (LMS) compatible with mobiles and mobile Augmented Reality applications are all examples of these discoveries. Augmented Reality is a developing technology which has the potential to influence the teaching-learning process [2]. Developments in Augmented Reality for mobile devices are rapidly increasing and this is reflected the increase in the usage of laptops worldwide. As mentioned by Horizon Report: Higher Education Edition, [9] Augmented Reality was one of the most developed emerging technologies in 2016. Bal and Bicen [10] state that the integration of QR codes into augmented reality technologies promotes learning in a shorter period of time via the usage of visuals. An analysis of Computer Education and Instructional Technology Department student grades reveals that the success rate in the computer hardware courses is low. With the integration of computers into every field, hardware knowledge has increasingly become significant. Hardware and software knowledge are regarded as the minimum knowledge any Computer Education and Instructional Technology Department graduate should have. Kehagias [11] states that students should think of computers as a magical black box which runs programmes automatically. Hence, computer hardware and software courses are regarded as an important part of undergraduate syllabi. The IEEE Computer Society and Association approve that these courses are a significant part of the curriculum in departments related to computer science. Zhoua [12] states that computer hardware courses include microcomputer principle, assembly language and interface technology, which are all difficult for students to apply. Liu [13] in his study claims that the role of basic hardware courses and the teaching models implemented are not sufficient enough to develop students' skills. Additionally, Chen [14] emphasizes the importance of implementing a learner-centered approach in applied courses in computer technologies departments. Moreover, there are many other studies which claim that the implementation of a student-centered approach to the teaching of computer science courses would lead to a higher success rate. Tok [15] states that reflective thinking has been identified as a general skill that teachers need to be proficient in; and thus, to enable a satisfactory proficiency level in this skill, it is important that teacher training courses include information on reflective thinking and there is an improved attitude towards it. Bosque, Martinez, \& Torres, [16] indicated that in their study the application of augmented reality as a strategy to increase the percentage of achievement of the students in the structured programming subject is consistent with the learning outcomes. However, a literature review of augmented reality in hardware courses revealed no study with a concrete conclusion.

This study aims to determine the benefits and limitations of AR applications in computer hardware education, when used as a supplementary technology, as well as examining their impact on reflective thinking skills. It is believed that Computer Education and Instructional Technologies students' reflective learning skills and their views on using AR applications in hardware courses are important because these 
students, who are receiving an education to ensure the integration of technology into learning environments and ensure its effective use, will one day become teachers themselves.

\section{Theoretical Background}

\subsection{Augmented reality}

Mehler-Bicher et al. [17] state that despite the continual increase of AR applications and the rapid advancement of the existing technology, a consistent definition of AR does not exist. In a most general term, augmented reality (AR) is defined as "a real world context that is dynamically overlaid with coherent location or context sensitive virtual information" [19]. Nincarean et al. [2] define augmented reality applications as the integration of virtual objects into real scenes.

Augmented reality applications must have three basic characteristics: (1) the combination of virtual and real objects in a real environment (2) an interactive study in a real-time environment (3) a consistency between the real and virtual objects [18]. In a study [20] it is emphasized that augmented reality is studied under two categories which are: optical and video-based technologies. The difference between the two technologies is the way the scene integrating the real and the virtual world is viewed. While in optical systems the scene is shown in the real world via glasses, in videobased technologies the scene is showed on a monitor or mobile device screen. Alkhattabi [5] states that it is more accurate to think of AR applications as a concept rather than a type of technology. Furthermore, Alkhattabi indicates that AR does not substitute real objects by placing them into a real environment; instead, it has a supportive role in students' experiences and enables them to benefit from the real-life opportunities it provides. Similarly, Nincarean et al. [2] claim that augmented reality environments increase student-student and student-teacher interaction and enable cooperative learning; hence, they increase student motivation. With the increase of mobile device usage so has the potential to use Augmented Reality applications on these devices. In some studies, Augmented Reality applications have been used with mobile devices by being integrated with QR codes. According to Wang et. al. [4], the utilization of AR applications in different fields of computer science has supported the increase in student motivation to learn the course content and also in the increase in their pedagogical strategies. Furthermore, researchers claim that augmented reality environments supported by mobile devices, where learning takes place with students involving their emotions and prior knowledge, can create more effective learning environments. According to Schrier [21] by using augmented reality applications, students can gain many $21^{\text {st }}$ century skills, such as interpretation, critical thinking, problem-solving, information management, group work and flexibility. Students should use Augmented Reality applications both at home and during lessons and give feedback to stimulate future studies. QR codes enable Scavenger hunts to be used on smartphones too, for example, learn mathematics or library categorization. Students can help AR technology developers by sharing their experiences with them. While 
learning the digestive system, students could use AR applications on their mobile phones and achieve their learning goals easily [22].

Currently there are some limitations to the use of Augment Reality; these are as follows: student mobile phones may not be compatible with augmented reality applications, lessons may not be able to be conducted effectively if teachers do not have the necessary technological skills [23]; both teachers and students can be trained to integrate these technologies into education.

\subsection{Reflective Thinking}

Reflective thinking, which is an approach that has been profoundly studied by researchers [24] enables the integration of theory and application, thought and practice and is defined as a process of reaching new values by the combination of past experiences, practices and theories [25]. Similarly, another researcher [26] explains reflection in education as students concentrating on a subject and the conscious analysis of it. On the other hand, a researcher [27] describes reflection as the whole of examination methods and problem solution activities. Some researchers [28] state that reflective learning encourages learners to gain a deeper understanding of the course content and that it provides them with the opportunity to comprehend their own learning process. Moreover, reflective learning aims to develop life-long learning skills by using learners' prior knowledge and enabling them to gain new experiences. Within the last 20 years, the literature on reflection abounds with examples of discussions on reflection developing learners' skills and promoting a deeper understanding [29]; a researcher [30] draws attention to teacher training, claiming that reflective tasks are a prominent paradigm in teacher training. Along similar lines, a researcher [31] explains that with this model of teaching, teachers are also able to discover their own methods and restructure their own knowledge. In addition to this, some researchers [32] report that the reflective teaching method will enable teachers to be analytical of their own teaching methods, and thus, will help them gain the experience of improving their teaching methods. It is supported by a researcher [30] who states reflective methods raise teachers' awareness of teaching, and therefore, have a positive influence on teaching methods. Authors in an article [33] point out that it is highly important for students that teachers use reflective methods in the classroom; yet, add that reflective thinking is a challenging skill for students to achieve. In short, teachers knowing strategies to implement reflective activities in class has a positive impact on students' reflective thinking skills. Reflective teaching, which has brought a new perspective to the learning-teaching process, enables teachers to improve their own teaching activities in-line with student needs [34]. Reflective teaching, which is considered to be a significant factor in improving students' learning habits and in the cooperation among teachers [35], also plays an important role in training teacher candidates. Reflection, which is particularly useful in helping teacher candidates to think like a teacher, is viewed as an inseparable component of teacher training [36]. In the same study authors emphasize that there are a very limited number of studies conducted to answer the query: "how to teach reflection". Harford and MacRuairc [43] state that although most teachers are aware of the origins and the development of 
the implementation of reflection and its significance, they are inexperienced in implementing it themselves. In this regard, it is believed that this study, which presents reflective implementations, will benefit teacher candidates and will contribute to the teaching profession.

\section{Method}

This study is a mixed method in which qualitative and quantitative data are used together. The study was designed according to pre-test post-test research model with experimental and control groups. Table 1 illustrates the design of the study.

Table 1. Research Design

\begin{tabular}{|l|l|l|l|}
\hline \multicolumn{1}{|c|}{ Group } & \multicolumn{1}{c|}{ Pre-test } & \multicolumn{1}{c|}{ Implementation } & \multicolumn{1}{c|}{ Post-test } \\
\hline Experimental & Reflective learning scale & $\begin{array}{l}\text { Augmented reality and reflec- } \\
\text { tive activities }\end{array}$ & $\begin{array}{l}\text { Reflective learning scale } \\
\text { Interviews }\end{array}$ \\
\hline Control & Reflective learning scale & Reflective activities & Reflective learning scale \\
\hline
\end{tabular}

62 students studying at the Computer Education and Instructional Technology department and taking the hardware course participated in the study. Students were assigned to experimental and control groups by looking at the last two digits of their student numbers; students' whose student number ended in an even number were assigned to the control group and students who had an odd number were assigned to the experimental group. Thus, there were 30 teacher candidates in the experimental group and 32 in the control group. $32 \%$ of the study participants were female and $68 \%$ were male. The teacher candidates, who were on average 22 years of age, will work at secondary school level institutions after they graduate. In order to identify the impact of reflective teaching methods, assisted with Augmented Reality, on the teacher candidates' reflective thinking skills, a "Reflective Thinking" scale and "Online Journals" were used, and an "interview form" was used to identify the teacher candidates' feelings and views regarding the execution of the hardware course using AR.

\subsection{Reflective thinking scale}

This study, which AR applications were implemented, aimed to identify the influence of AR activities on teacher candidates' reflective thinking skills. In the study, the "reflective thinking scale" developed in the year 2000 by Kember and friends [37], was used. The scale consists of 4 dimensions and 16 statements; the dimensions are as follows: "habitual action (1-5-9-13)", "understanding (2-6-10-14)", "reflection (3-711-15)" and "critical reflection (4-8-12-16)". Perkowska-Klejman [38] reflection levels have been explained in the following table. In addition, the whole scale's Cronbach's alpha value was calculated as $(0.89)$. These item features are on a 5-point response scale ( $1=$ definitely disagree; $5=$ definitely agree). Some of the statements in the scale are as follows: Habitual actions: "In this course, we do things so many times that I have started doing them without thinking”, Understanding: "I need to 
understand the material taught by the teacher in order to perform practical tasks." Reflection: "I like to think over what I have been doing and consider alternative ways of doing it", Critical Reflection: "During this course, I discovered flaws in what I had previously believed to be right". The scale was used to determine both groups' reflective thinking skills prior to and also after the study. The Repeated Measures ANOVA technique was used in the analysis of the data obtained from the scale. The values obtained from the analysis were interpreted with a significance level of 0.05 .

Table 2. Description levels of reflections [38]

\begin{tabular}{|l|l|}
\hline $\begin{array}{c}\text { Level of student's } \\
\text { reflexivity }\end{array}$ & \multicolumn{1}{c|}{ Description of the level of reflection } \\
\hline Habitual action & $\begin{array}{l}\text { Activity that is learnt through frequent, automatically use. } \\
\text { "In professional practice, habitual action occurs when a procedure is followed with- } \\
\text { out significant thought about it."[37] }\end{array}$ \\
\hline Understanding & $\begin{array}{l}\text { Thoughtful activity of individuals in which they use their existing knowledge and } \\
\text { achieve comprehension of different subjects or phenomena. In this case, there is an } \\
\text { attempt to understand the topic or concept. Most students begin at this level. In their } \\
\text { writing they rely heavily on what the textbook or teacher has said. }\end{array}$ \\
\hline Reflection & $\begin{array}{l}\text { The critique and appraisal of assumptions about the content or process of problem } \\
\text { solving. At this level, students not only have accurate understanding, they reflect on } \\
\text { that understanding and are able to relate it to personal experiences, or they make } \\
\text { practical applications. }\end{array}$ \\
\hline Critical reflection & $\begin{array}{l}\text { This highest level of reflection implies the transformation of a perspective. Teachers } \\
\text { should not expect this level of reflection early or often while students are developing } \\
\text { their reflective skills. Students start by recognizing their beliefs and accompanying } \\
\text { assumptions. Something (new information, new experiences) disrupts that belief } \\
\text { system, thereby forcing students to reconstruct or reform it. }\end{array}$ \\
\hline
\end{tabular}

\subsection{Interview form}

At the end of the process, in order to determine teacher candidates' views on the application, a semi-structured interview form prepared by the researchers was used with the candidates who took the Augmented Reality assisted hardware course. On the form, there are questions to identify the effectiveness and difficulties of Augmented Reality applications. To ensure content validity, the questions in the form were prepared by referring to the related literature. In order to ensure clarity and suitability of the interview questions, five experts were consulted and necessary adjustments were made in light of their feedback. Interviews were carried out with 15 volunteer teacher candidates. To ensure that there was no loss of data during the interviews, they were recorded and later transcribed. The data obtained was analyzed using the in-depth content analysis method with the Nvivo 10 programme. To ensure the reliability of the qualitative data obtained the critical friends approach was used. One of the researchers analyzed the texts and the other one double-checked them. Yet, another researcher who was not involved in the study was requested to perform triangulation. 


\subsection{Preparation of Augmented Reality activities and online journals}

Küçük et al. [39] in their study, state that there are two types of AR which are: marker based and Global Positioning System-based (GPS). While GPS based systems have three components consisting of area and image descriptor devices, marker-based applications consist of 3 fundamental components which are: a book in which the markers are located, a device that converts the information in the markers into a digital domain and a screen showing a digital data in 3D or 2D. In this study, video and marker based AR technologies were used. A free application, Aurasma, was used as the augmented reality application. Aurasma enables 3D models and animations to be loaded on trackers like shapes and photos. An Aurasma-equipped mobile device, using the camera, scans and reads surroundings and presents the user with $3 \mathrm{D}$ videos and animations. Some of the three-dimensional hardware models were found on the net and downloaded and ones that could not be found were developed by the researchers. In the development of these 3D models Photoshop, Flash Mx and 3Ds Max were used.

These 3D models were integrated into previously prepared animations and videos using Aurasma. Markers related to specified topics were used. The 3D visuals which were downloaded from the net and later improved by the researchers can be turned around to be perceived from different angles and their dimensions can be changed. The course notes containing the markers were put into course handbooks which were prepared using Cliptomize, which can be accessed via the net for free of charge. The markers to be read were integrated into the handbooks. Figure 1 shows an example of the book which was prepared and the $3 \mathrm{D}$ visuals.

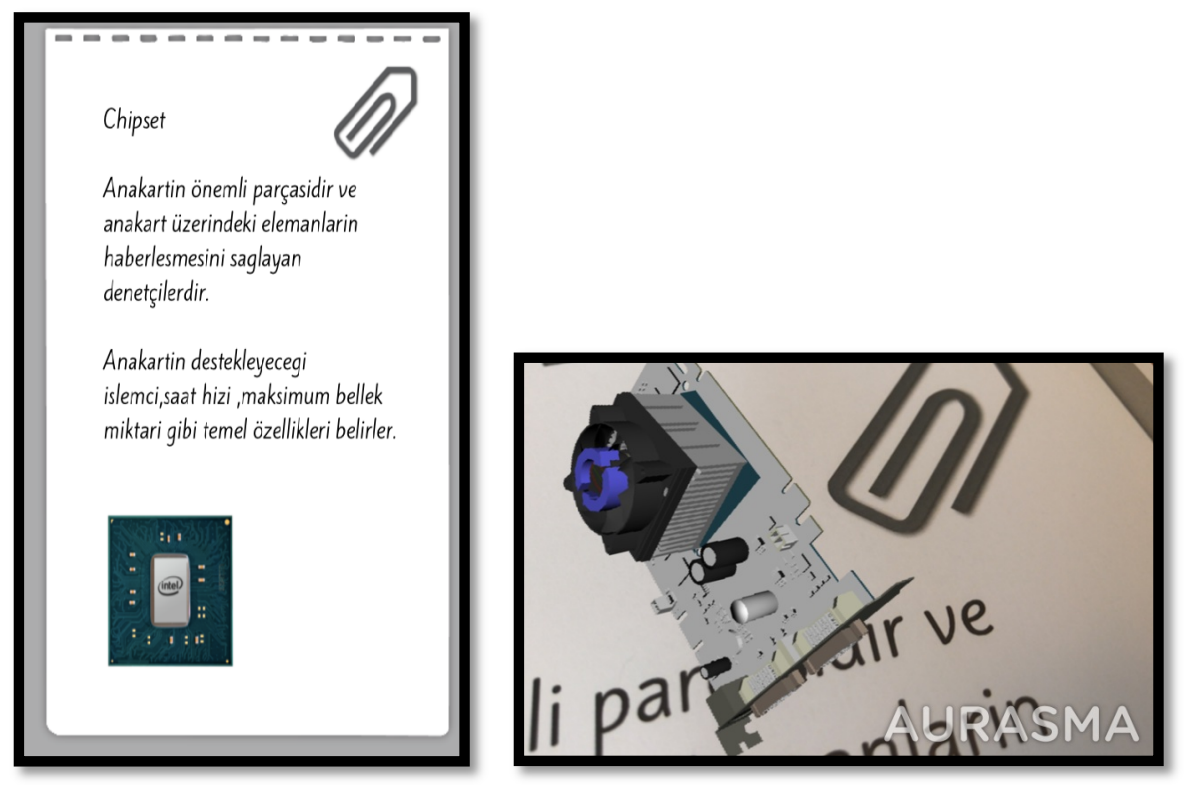

Fig. 1. An example from the developed book and 3D image when scanning 
In the study as well as Augmented Reality applications, reflective learning tasks were implemented. For the reflective learning tasks, the "journal plug-in" application was integrated into Moodle. Journal plug-in allows teachers to ask students to reflect on the course content. Students can edit and refine their replies and comments whenever they want.

\subsection{Implementation}

At the beginning of the study, the "reflective learning" scale was administered to both groups as a pre-test to determine whether both groups' learning skills were equal or not. The data obtained from reflective learning scale was analyzed and it was identified that both groups were similar in this sense. In order to ensure reliability, in both groups, the process was conducted by only one of the researchers. In the study which extended over an 8-week period, Moodle was used in both groups and the lessons were supplemented with reflective learning tasks. At the end of each lesson, the teacher candidates reported their experiences and queries related to the subject. Likewise, before starting to write their reflective diaries the teacher candidates were required to ask themselves questions similar to the following ones: "What did I see?, what did I learn?, what did I hear?, what can I do about ...?".Moreover, the instructor asked the teacher candidates to answer the following questions in the order that they appear: "Can you explain what you learned in the lesson?", "Could you write how you learnt?" and "Can you evaluate your learning style and strategies?" Hence, the teacher candidates recorded what they had learnt and simultaneously reflected on their own learning. Furthermore, the researcher shared questions related to the subject studied in class via Moodle ensuring that the teacher candidates thought about these questions and wrote a report including their learning reflections.

Similarly, during the class hours, not only the researcher but also the teacher candidates asked each other and the researcher's questions. The researcher gave constant feedback, both positive and negative, on the reports on reflective learning in the online journals. The teacher candidates were not given any training on using Moodle. As the department's regulations enforce the use of Moodle in all course students were familiar with the system. The online journal, which was added to the system via a plug-in, was introduced during the first lesson. Deadlines were announced to teacher candidates in both groups via Moodle. Moreover, the researcher set the homework tasks via Moodle and collected them from the teacher candidates, on the submission date.

Teacher Candidates' Roles and Tasks in Experimental Group: The course book that was designed by the researchers and the Aurasma application were downloaded by the teacher candidates. Throughout the term, the teacher candidates were required to watch $3 \mathrm{D}$ visuals and educational animations by read the markers on books with Aurasma. Throughout 8 weeks, the teacher candidates with their cooperative groups of 3-4 persons watched videos that were integrated into books where differently equipped solutions present. At the end of the 8 -week, the teacher candidates were asked differently equipped problems and required to find solutions. The teacher candidates produced solutions and presented their reports in the classroom environment 
by working with the cooperative learning groups. Doing this enabled targeted activities to be more effective.

Teacher Candidates' Roles and Tasks in Control Group: The teacher candidates in the control group attended the courses in a lab setting throughout 8 weeks. At the end of this 8 week duration, the teacher candidates were asked differently equipped problems and required to find solutions. The teacher candidates produced solutions and presented their reports in the classroom environment by working with the cooperative learning groups.

At the end of the study, the "reflective learning" scale was administered once again, as a post-test, in order to determine if there had been a rise in both groups' reflective learning skills.

\section{$4 \quad$ Results}

The findings of this study, which aimed to identify the impact of augmented reality applications on students' reflective learning skills and determine student opinions regarding augmented reality, are as presented below. The data analysis findings obtained from the reflective learning skills scale administered to the experimental and control groups, both before and after the implementation of the Augmented Reality and reflective learning tasks, were analyzed in the table below.

Table 3. Means for Pre-Post Test for both groups

\begin{tabular}{|c|c|c|c|c|c|c|c|c|c|}
\hline \multicolumn{2}{|c|}{} & \multicolumn{2}{c|}{ Habitual Actions } & \multicolumn{2}{c|}{ Understanding } & \multicolumn{2}{c|}{ Reflection } & \multicolumn{2}{c|}{ Critical Reflection } \\
\cline { 3 - 11 } & Mean & SD & Mean & SD & Mean & SD & Mean & SD \\
\hline \multirow{2}{*}{$\begin{array}{c}\text { Pre- } \\
\text { test }\end{array}$} & Control & $\mathbf{3 . 1 7 1 9}$ & .48125 & $\mathbf{2 . 5 1 5 6}$ & .45763 & $\mathbf{2 . 8 5 9 4}$ & .41122 & $\mathbf{2 . 3 7 5 0}$ & .44450 \\
\cline { 2 - 11 } & Augmented & $\mathbf{3 . 0 8 3 3}$ & .42717 & $\mathbf{2 . 6 5 8 3}$ & .31131 & $\mathbf{2 . 8 5 0 0}$ & .16867 & $\mathbf{2 . 3 4 1 7}$ & .37990 \\
\hline $\begin{array}{c}\text { Post } \\
\text { Test }\end{array}$ & Control & $\mathbf{3 . 0 7 8 1}$ & .37801 & $\mathbf{2 . 9 6 8 8}$ & .27496 & $\mathbf{3 . 3 2 0 3}$ & .30608 & $\mathbf{3 . 2 2 6 6}$ & .27208 \\
\cline { 2 - 11 } & Augmented & $\mathbf{3 . 1 3 3 3}$ & .36397 & $\mathbf{2 . 9 4 1 7}$ & .36367 & $\mathbf{3 . 6 2 5 0}$ & .42421 & $\mathbf{3 . 6 1 6 7}$ & .36984 \\
\hline
\end{tabular}

As it can be seen from the table above, prior to the study the two groups' scores obtained from the four dimensions were close to one another. It was identified that, prior to implementing Augmented Reality and reflective learning tasks, students obtained the highest score from the habitual actions dimension. According to this, it can be said that students act on the habitual actions step, and while demonstrating learning, they repeat behaviors they have already acquired. Moreover, it can be said that while students assessed the problem-solving process, they were able to decide on the best solution; however, they did not acknowledge the hypotheses. After the implementation of Augmented Reality and reflective learning tasks to the students in both groups, it was observed that there was an increase in all of the dimensions except for in the habitual actions dimension. This was an expected outcome as reflective learning tasks were implemented in both groups. However, in order to determine whether Augmented Reality applications have an influence on reflective learning, Repeated Measures analysis was employed to the obtained data. It was determined that there was no difference between the groups' pre-test-post-test scores in the Habitual actions 
$\left(F_{1-60}=1.037, p>0.05\right)$ and Understanding $\left(F_{1-60}=1.981, p>0.05\right)$ levels. However, according to the findings after the study, there was a significant difference between the groups' scores in reflective thinking $\left(F_{1-60}=7.600, p<0.05\right)$ and critical reflective $\left(F_{1-60}=13.997, p<0.05\right)$ levels. According to these findings, it can be said that supplementing reflective learning tasks with Augmented Reality applications have a positive impact on Reflective and Critical Reflective skills. It was also determined that at the end of the course, students experience a change in the way they viewed themselves and that they were able to give up behaviors which they adhered to. Furthermore, according to the findings, students who had claimed that their class notes were sufficient to study for a subject after the study expressed that their notes alone were not adequate enough. In short, it can be said that Augmented Reality applications do not increase habitual actions but higher level skills: reflective and critical reflective learning.

Descriptive analysis was employed to the online journal contents in order to identify which reflective thinking dimensions the teacher candidates were using while completing the tasks in the online journals. The teacher candidates' statements were categorized according to the reflective teaching scale, to identify which dimension they were related to. When the online journals were analyzed in depth, it was seen that all of the teacher candidates receiving an augmented reality assisted education, had entered the system. There were a total 180 entries. On average, the teacher candidates had each uploaded 6 entries during the 8 weeks. While in the first week there were only a few entries, the number of entries increased in the following weeks. Due to two participants' online journals not being in line with the study's intended target, they were disregarded; and thus, 165 entries were analyzed as part of the study.

Table 4. Opinions on reflective dimensions

\begin{tabular}{|l|c|}
\hline & f \\
\hline Habitual Actions & 14 \\
\hline Understanding & 45 \\
\hline Reflective & 121 \\
\hline Critical Reflective & 49 \\
\hline
\end{tabular}

As it can be seen from the table above, the teacher candidates reflected on all dimensions of reflective thinking. It can be said that the teacher candidates mainly exhibited the reflective thinking manner. When the findings attained from the online journals are examined, it can be said that they correspond to the data obtained from the reflective learning scale. The difference is that according to the findings attained from the scale the teacher candidates' reflective and critical reflective skills were more or less at the same level; whereas, based on the descriptive analysis it can be said that the teacher candidates used critical reflective skills more often than reflective thinking. Below are some samples of teacher candidates' entries according to the different dimensions: 
St2: "I studied the hardware book given to us this week via my mobile phone as instructed by my instructor".

St8: "This week, as every other week, we scanned the markers on the pages our instructor specified with our mobile devices and watched the videos and 3Ds".

These comments made by St 2 and St 8 were evaluated under the habitual actions dimension. As it can be seen the teacher candidates progressed according to instructions given by the instructor. However, as seen in the table there were not many habitual actions comments, moreover, statements which fell into the habitual actions dimension were mainly given in the first two weeks.

St12: "To watch the $3 D$ models and videos you need to understand the applications the instructor is talking about...".

St20: "Today in the lesson our instructor used the demonstration method. Later on, our instructor asked us to read the books that were specially compiled for us on our phones and watch some videos, at the end of the lesson there was a question-answer session."

St12 and St20's reflective writings from the online journals were analyzed under the understanding dimension because as seen in the samples above St12 stated the need to understand the applications the instructor talks about and St20 explained the methods and strategies used in the class.

St14: "Today we learnt about Serial, USB and Parallel ports. The instructor asked about the differences between these ports. We tried to answer from what we knew. Because of our responses, the instructor asked us to read the markers on the relevant page and study the $3 D$ view of the ports. Thus, we found out what the difference was by inquisitively studying the $3 D$ models and the required information. We engaged in the lesson because of the question and answer method".

St4: "In the lesson today we learnt how to place RAMs into the slots on the mainboard. The instructor taking into account the different learning styles in class, first, asked us to watch the videos and then explained the subject using the demonstration method. She explained the types of RAMs in detail and how they are placed into slots and to ensure that we all understood what she explained, she made all students follow the steps. Thus, we actively participated in the lesson".

These statements, where the teacher candidates explain and interpret the instructor's actions to ensure active participation and which they state the outcome as well as justifying the use of the instructor's methods and teaching strategies, were associated with the reflective dimension.

St26: "In order to learn how to assemble the hardware parts as a group we put together the system unit which was disassembled. I maintained an effective communication flow within my group. The instructor asked us some questions now and then. Yet, I realized that I didn't exactly know the differences between the types of RAMs". 
St29: "While presenting our projects I felt anxious and I couldn't use my voice effectively, so I found it difficult to maintain my classmates' attention. I spent days on preparing my presentation on the importance of Hardware and Software. I used presentation software and tried to do my best by bearing in mind the principles of giving a presentation which I had learnt in my courses. In fact, I had planned to show animations using Aurasma, the Augmented Reality application we used in this course. But, because of my anxiety, my presentation didn't go as I would have liked".

These reflective statements were evaluated under the critical reflection dimension because the teacher candidate, reflected on an experience and explained what happened with justifications and realized he made some mistakes and included selfcriticism.

The findings from the interviews, which aimed to determine the advantages and challenges regarding AR applications carried out with students who took the computer hardware course for 8 weeks, were categorized according to their themes and presented in a table.

Table 5. Advantages and challenges of $A R$ applications

\begin{tabular}{|l|l|c|}
\hline \multicolumn{1}{|c|}{ Theme } & \multicolumn{1}{c|}{ Code } & f \\
\hline \multirow{4}{*}{ Advantages } & Enhance enjoyment & 15 \\
\cline { 2 - 3 } & Increase motivation & 13 \\
\cline { 2 - 3 } & Increase interest & 11 \\
\cline { 2 - 3 } & Help to understand & 11 \\
\hline \multirow{2}{*}{ Challenges } & Technical problems & 5 \\
\cline { 2 - 3 } & Expensive technology & 2 \\
\hline
\end{tabular}

The teacher candidates who took the computer hardware course with Augmented Reality technologies stated that they were extremely satisfied with the tasks implemented. Furthermore, the teacher candidates, who mainly gave positive feedback on the reflective learning tasks assisted with augmented reality, stated that Augmented Reality applications were intriguing and they had fun while learning.

St2: "I can say that in this course, where we had books specially designed for augmented reality and which in activities were carried out via our phones, was much more enjoyable than other courses. Moreover, the diaries which in we explained what we did in the course and where we shared our opinions improved our writing experience".

St17: "We had a really dense timetable, so we really looked forward to courses which used different applications; we had fun and learnt at the same time."

When we analyze student comments, we can say that they regard Augmented Reality applications as fun and interesting. Moreover, most of the students stated that using Augmented Reality applications in the hardware course increased their motivation and made the course easier to follow. 
St22: "After our instructor gave us the theory of the content of the lesson, she supplemented it with 3Ds and animations with AR; this made learning a lot easier. I believe that we will make fewer mistakes when we put this knowledge into practice".

St3: "AR applications increased student motivation. By using animations with AR applications we watched how to assemble a main card before actually doing it and this made learning easy and we were able to do the necessary additions to the main cards without making any mistakes. Completing a flawless assembly is an important skill as mistakes can damage computer parts."

When the teacher candidates were asked about the challenges they experienced while using Augmented Reality applications in their Computer Hardware course, they stated that they did not face many difficulties and the difficulties they did experience were technical. They also stated that AR applications were expensive.

St11: "We did not really experience many difficulties while using AR applications, sometimes we had to use our own $3 G$ s as we could not connect to the internet in the labs".

St9: "In this application, which we enjoyed using, our phones were not sufficient or when we were out of the classroom we had difficulty scanning the markers because of the reflection of light".

St5: "Although Augmented Reality applications are useful, they are an expensive technology. We needed phones with a good camera and screen and we needed to have $3 G$ when we were working out of school; apart from these, the application was easy to use. We only experienced some difficulties while scanning the markers."

As it can be seen from the explanations it can be said that the implementation of Augmented Reality applications in the Computer Hardware course was fun, interesting, motivating and it also made learning the subjects simpler and lessened the chance of making a mistake. When the challenges of Augmented Reality applications are analyzed, it can be said that internet connection, technical difficulties in scanning the markers due to light reflections and the expense are the main ones.

\section{$5 \quad$ Discussion and Conclusion}

A total of 62 Computer Education and Instructional Technology students participated in this study in experimental and control groups, for 8 weeks using AR applications in their Computer Hardware course. The study aims to determine teacher candidates' views and the effect of Augmented Reality - a technology which enables objects from the real world to merge with virtual ones interacting synchronously - on reflective learning when implemented with reflective learning tasks.

The results of the study indicate that AR applications have a positive impact on reflective learning skills and are proven useful when implemented in a computer hardware course. It was observed that teacher candidates' whose reflective learning skills 
were studied in the experimental and control groups Reflective and Critical Reflective skills improved. The findings suggest that in both the experimental and in the control group, reflective thinking was the most frequently used way of thinking. In their study Kember et. al. [37] revealed that critical reflective emerges when the reasons for a particular action or when assumptions are being explored; thus reflection is the stage which occurs the most while not being observed much. In this study, it can be said that the experimental groups' Reflective and Critical Reflective skills, which were supplemented with AR applications, were significantly higher. There was an increase in both groups skills because the reflective learning tasks were implemented in both, however, it can be said that AR applications have a greater impact on reflective learning skills. In a study conducted in the year 2008 [15], it is claimed that reflective learning tasks also have a positive impact on the teacher candidates' performances. Çiğdem and Kurt [40] in their study on blogs reached similar results. As a result, both AR applications and reflective learning tasks are effective in teacher training and education.

Another finding is teacher candidates were satisfied with the Augmented Reality applications. The results suggest that the Augmented Reality applications developed for the hardware course were extremely enjoyable, motivating and intriguing. Bicen and $\mathrm{Bal}[10]$ in their study regarding AR applications' effects on student success in hardware courses, came to the conclusion that the AR group achieved higher. As it can be seen from this study, even though achievement rates were not considered, AR applications had a positive impact on teacher candidates' views. Another author [41] states that implementing different types of materials affects student roles positively. Another result derived from the study is that students who took the hardware course supplemented by Augmented Reality applications learnt the subject easier and made no mistakes while assembling the hardware. In a similar study revealed that students using AR technologies spent less time while assembling a main card and made fewer mistakes when compared to students who had not [42].

When the findings regarding the challenges experienced while implementing Augmented Reality applications in the hardware course are analyzed, it is revealed that these are internet connection, camera quality and the requirement of a fee. In further studies, the markers used in the AR applications can be simpler, thus, they will be able to be scanned with lower quality cameras and the expenses will be reduced. It is foreseen that any technical errors that occur during the process of the study will be caused by the usage of different types of devices. In a study [18] indicated that using different types of devices for AR applications can cause more technical problems.

As a result, in this study where Augmented Reality applications assisted with reflective learning skills were implemented in a computer hardware course, teacher candidates generally reported positive views and suggestions regarding AR applications. AR has a great potential as a means of highlighting interesting features via multimedia content on mobile devices. However, as in all studies, this study had its limitations. The most important limitation was implementing AR applications only in a computer hardware course. Further studies could be conducted to determine its effect in other courses. Moreover, areas of AR applications which have not been researched at secondary school level can be identified and studied and the teacher as- 
pect can be included. Furthermore, it is recommended that in further studies in this field, researchers can take this study's findings into account.

\section{References}

[1] Gutiérrez, J. M., Fabiani, P., Benesova, W., \& Meneses, M. D. (2015). Augmented reality to promote collaborative and autonomous learning in higher education. Computers in Human Behavior, 51(2015), 752-761. https://doi.org/10.1016/j.chb.2014.11.093

[2] Nincarean, D., Alia, M. B., Halim, N. D. A., \& Rahman, M. H. A. (2013). Mobile Augmented Reality: The Potential for Education. Procedia - Social and Behavioral Sciences, 103, 657-664. https://doi.org/10.1016/j.sbspro.2013.10.385

[3] Mayer, R. E. (2009). Multimedia learning. (2. Ed.) New York: Cambridge University Press. https://doi.org/10.1017/CBO9780511811678

[4] Wang, Y., Vincenti, G., Braman, J., \& Dudley, A. (2013). The ARICE Framework: Augmented Reality in Computing Education. International Journal of Emerging Technologies in Learning (iJET), 8(6), 27-34. https://doi.org/10.3991/ijet.v8i6.2809

[5] Alkhattabi, M. (2017). International journal of emerging technologies in learning. International Journal of Emerging Technologies in Learning (iJET) (Vol. 12, No. 2). https://doi.org/10.3991/ijet.v12i02.4283

[6] Chen, C. H., Ho, C.-H., \& Lin, J.-B. (2015). ScienceDirect The development of an augmented reality game-based learning environment. Procedia -Social and Behavioral Sciences, 174, 216-220. https://doi.org/10.1016/j.sbspro.2015.01.649

[7] Kong, S. C., \& Song, Y. (2015). An experience of personalized learning hub initiative embedding BYOD for reflective engagement in higher education. Computers \& Education, 88, 227-240. https://doi.org/10.1016/j.compedu.2015.06.003

[8] Song, Y., \& Kong, S. C. (2017). Affordances and constraints of BYOD (Bring Your Own Device) for learning and teaching in higher education: Teachers' perspectives. Internet and Higher Education, 32, 39-46. https://doi.org/10.1016/j.iheduc.2016.08.004

[9] Horizon Report: 2017 Higher Education Edition. (n.d.). Retrieved from http://cdn.nmc.org/media/2017-nmc-horizon-report-he-EN.pdf

[10] Bicen, H., \& Bal, E. (2016). Determination of student opinions in augmented reality. World Journal on Educational Technology, 8(3), 205-209. https://doi.org/10.18844/ wjet.v8i3.642

[11] Kehagias, D. (2016). A Survey of Assignments in Undergraduate Computer Architecture Courses. International Journal of Emerging Technologies in Learning (iJET), 11(6), 6872. https://doi.org/10.3991/ijet.v11i06.5776

[12] Zhoua, Y. (2011). Research and Practice of Course Design on Microcomputer Principle and Interface Technology. Procedia Engineering, 15, 4211-4215. https://doi.org/10.1016/ j.proeng.2011.08.790

[13] Liu, L. (2014). Study on Research-oriented Teaching for Hardware Courses of Software Engineering Major. In G. Lee (Ed.), Advances in Education Research (pp. 297-303). Shenzhen: Luiss University Press. Retrieved from http://apps.webofknowledge.com/full_record.do?product=WOS\&search_mode=GeneralSe arch\&qid=1\&SID=T1 mHyOgCC2SsKmwqyBS\&page=1\&doc=3\&cacheurlFromRightCli $\mathrm{ck}=\mathrm{no}$

[14] Chen, Z.Y. (2006). Student-centred pedagogy in Computer Application course design. The China Papers, 11, 73-77. 
[15] Tok, S. (2008). The impact of reflective thinking activities on student teachers's attitudes toward teaching profession, performance and reflections. Education and Science, 33(149), 104-117.

[16] Bosque, L. Del, Martinez, R., \& Torres C, J. L. (2015). ScienceDirect 2015 International Conference on Virtual and Augmented Reality in Education Decreasing Failure in Programming Subject with Augmented Reality Tool. Procedia - Procedia Computer Science, 75, 221-225. http://doi.org/10.1016/j.procs.2015.12.241

[17] Mehler-Bicher A, Reiß M, Steiger L. (2011) Augmented reality: Theorie und Praxis. Oldenbourg, München. https://doi.org/10.1524/9783486706888

[18] Akçayır, M., Okçe Akçayır, G. €, Pekta, H. M., \& Ocak, M. A. (2016). Augmented reality in science laboratories: The effects of augmented reality on university students' laboratory skills and attitudes toward science laboratories. https://doi.org/10.1016/j.chb.2015.12.054

[19] Klopfer, E., \& Squire, K. (2008). Environmental Detectives - the development of an augmented reality platform for environmental simulations. Educational Technology Rese arch and Development, 56 (2), 203-228. https://doi.org/10.1007/s11423-007-9037-6

[20] Somyürek, S. (2014). Öğretim Sürecinde Z Kuşağının Dikkatini Çekme: Artırılmış Gerçeklik. Eğitim Teknolojisi Kuram ve Uygulama, 4(1), 63. https://doi.org/10.17943/ etku. 88319

[21] Schrier K. (2006). Using augmented reality games to teach 21 st century skills. In Proceedings of ACM SIGGRAPH 2006 Educators program 2006, p.15. https://doi.org/10.1145/ 1179295.1179311

[22] Coulby, C., Hennessey, S., Davies, N., \& Fuller, R. (2011). The use of mobile technology for work-based assessment: the student experience. British Journal of Educational Technology, 42(2), 251-265. https://doi.org/10.1111/j.1467-8535.2009.01022.x

[23] Dunleavy, J. \& Milton, P. (2009) What did you do in school today? Exploring the Concept of Student Engagement and its Implications for Teaching and Learning in Canada. Toronto: Canadian Education Association.

[24] Colomer, J., Pallisera, M., Fullana, J., Burriel, M. P., \& Fernandez, R. (2013). Reflective learning in higher education: A comparative analysis. Procedia - Social and Behavioral Sciences, 93, 364-370. https://doi.org/10.1016/j.sbspro.2013.09.204

[25] Koong, C. S., Yang, T. I., Wu, C. C., Li, H. T., \& Tseng, C. C. (2014). An investigation into effectiveness of different reflective learning strategies for learning operational software. Computers \& Education, 72, 167-186. https://doi.org/10.1016/j.compedu.2013.11.003

[26] Higgleton, E. (1995). Chambers English essential English dictionary. London: University of Cambridge Press

[27] Henderson, G. J. (1996). Reflective teaching: The study of constructivist practices. New York: Cornell University Press

[28] Yasin, R. M., Rahman, S., \& Ahmad, A. R. (2012). Framework for reflective learning using portfolios in pre-service teacher training. Procedia - Social and Behavioral Sciences, 46, 3837-3841. https://doi.org/10.1016/j.sbspro.2012.06.156

[29] Rushton, D., \& Lahlafi, A. (2013).Development, implementation and impact of active and reflective learning initiatives to improve web searching skills of international business students at Sheffield Hallam University, UK. Procedia - Social and Behavioral Sciences, 93, 885 -894. https://doi.org/10.1016/j.sbspro.2013.09.298

[30] Liou, H. C. (2001). Reflective practice in a pre-service teacher education program for high school English teachers in Taiwan, ROC. System, 29, 197-208. https://doi.org/10.1016/ S0346-251X(01)00011-2

[31] Kilpatrick, C., Hart, L., Najee-ullah, D., \& Mitchem, P. (1997). Reflective Teaching Practice by University Faculty: Rationale and Case Study in Computer Science. Frontiers in 
Education Conference, 1997. 27th Annual Conference. Teaching and Learning in an Era of Change. Proceedings, 3

[32] Cruickshank, D. \& Applegate, J. (1981). Reflective teaching as a strategy for tender growth. Retrived from http://www.ascd.com/ASCD/pdf/journals/ed lead/el 198104 cruickshank.pdf

[33] Bayrak, F., \& Usluel, Y. K. (2011). The effect of blogging on reflective thinking skill. $H$. U. Journal of Education, 40, 93-104

[34] Galea, S. (2012). Reflecting reflective practice. Educational Philosophy and Theory: Incorporating ACCESS, 44(3), 245-258https://doi.org/10.1111/j.1469-5812.2010.00652.x

[35] Fatemipour, H. (2013). The efficiency of the tools used for reflective teaching in ESL contexts. Procedia - Social and Behavioral Sciences, 93, 1398-1403 https://doi.org/10.1016/ j.sbspro.2013.10.051

[36] Jay, J. K., \& Johnson, K. L. (2002). Capturing complexity: a typology of reflective practice for teacher education. Teaching and Teacher Education, 18, 73-85. https://doi.org/10.1016/S0742-051X(01)00051-8

[37] Kember, D., Leung, D., Jones, A., Loke, A. Y., McKAy, J. Sinclair, K., Tse, H., Webb, C., Wong, F.K.Y., Wong, M., \& Yeung, E. (2000). Development of a questionnaire to measure the level of reflective thinking. Assessment and Evaluation in Higher Education, 25, 380-395. https://doi.org/10.1080/713611442

[38] Perkowska-Klejman, A. (2013). Reflective thinking of pedagogy students. International Reflective Practice Conference, 9th - 11th September 2013, Swansea.

[39] Küçük, S., Yılmaz, R., \& Göktaş, Y. (2014). Augmented Reality for Learning English: Achievement, Attitude and Cognitive Load Levels of Students. TED Education and Science, 39(176). https://doi.org/10.15390/EB.2014.3595

[40] Çiğdem, H., \& Kurt, A. A. (2012). Adaptation of Reflective Thinking Scale to Turkish. Uludă̆ Üniversitesi Eğitim Fakültesi Dergisi, 25(2), 475-493

[41] Tugun, V. (2016). Validity and Reliability Dissertation of the Scale Used for Determination of Perceptions and Attitudes of Teacher's Proficiency in Tablet PC-Supported Education. Cypriot Journal of Educational Sciences, 11(2), 51-57. https://doi.org/10.18844/ cjes.v11i2.617

[42] Sırakaya, M. (2016). Artırılmış Gerçekliğin Uygulamalı Eğitimde Kullanımı: Anakart Montaj1. Journal of Kirsehir Education Faculty, 17(3), 301-316.

[43] Harford, J., \& MacRuairc, G. (2008). Engaging student teachers in meaningful reflective practice. Teaching and Teacher Education, 24, 1884-1892 https://doi.org/10.1016/j.tate. $\underline{2008.02 .010}$

\section{$7 \quad$ Authors}

Fezile Ozdamli is with the head of Department of Computer Education \& Instructional Technology, Near East University, P.O. Box: 99138, Nicosia, North Cyprus (email: fezile.ozdamli@neu.edu.tr)

Cigdem Hursen works as an associate professor at Near East University. In October 2013, she was appointed to be the chairperson of the department of Social Sciences of Near East University, Atatürk Education Faculty. In the same year, she was also appointed as the chairperson of the department of Measurement and Evaluation. She is also one of the board members of the Association of Cyprus Educational Sciences.

Article submitted 27 June 2017. Published as resubmitted by the authors 15 August 2017. 